\title{
Thalamocortical Axons Extend Along a Chondroitin Sulfate Proteoglycan-enriched Pathway Coincident with the Neocortical Subplate and Distinct from the Efferent Path
}

\author{
Alma R. Bicknese, ${ }^{a}$ Allan M. Sheppard, ${ }^{b}$ Dennis D.M. O'Leary, ${ }^{\circ}$ and Alan L. Pearlman \\ Departments of Cell Biology, Neurology, Pediatrics, and Anatomy and Neurobiology, Washington University School of \\ Medicine, St. Louis, Missouri 63110
}

\begin{abstract}
The distinct axonal tracts of the mature nervous systèm are defined during development by sets of substrate-bound and diffusible molecular signals that promote or restrict axonal elongation. In the adult cerebral cortex, efferent and afferent axons are segregated within the white matter. To define the relationship of growing efferent and afferent axons in the developing murine cortex to chondroitin sulfate proteoglycans (CSPGs) in the pericellular and extracellular matrix, we used the fluorescent tracer Dil to determine axonal trajectories and immunolabeling to disclose the distribution of CSPGs. Axons of neurons in the preplate are the first to leave the cortex; they arise in the CSPG-rich preplate and extend obliquely across it to enter the CSPG-poor intermediate zone. Slightly later, axons of cortical plate neurons extend directly across the CSPG-rich subplate, and then turn abruptly to run in the upper intermediate zone. In contrast, once afferent axons from the thalamus reach the developing cortical wall, their intracortical trajectory is centered on the CSPG-rich subplate, above the path taken by efferent axons.

Our findings demonstrate a molecular difference between the adjacent but distinct efferent and afferent pathways in developing neocortex. Early efferents cross the subplate and follow a pathway that contains very little CSPG, while afferents preferentially travel more superficially within the CSPG-rich subplate. Thus, CSPGs and associated extracellular matrix (ECM) components in the preplate/subplate do not form a barrier to axonal initiation or outgrowth in the neocortex as they may in other locations. Instead, their distribution suggests a role in defining discrete axonal pathways during early cortical development.
\end{abstract}

\footnotetext{
Received Aug. 20, 1993; revised Nov. 19, 1993; accepted Nov. 30, 1993

We are grateful to Carol Boyd, Bindhu Gopalan, and Judy Speck for technical assistance, and to Drs. Janice Brunstrom, Brad Miller, and Rebecca Tuttle for comments on the manuscript. This work was supported by research grants to A.L.P. (EY00621, NEI) and D.D.M.O'L. (NS31 558, NINDS, and the Valley Foundation), and fellowship support to A.R.B. (NIH Training Grant NS07027) and A.M.S. (McDonnell Centers for Higher Brain Function and Cellular and Molecular Neurobiology, Washington University).

Correspondence should be addressed to Alan L. Pearlman, M.D., Department of Cell Biology, Box 8228, Washington University School of Medicine, 660 South Euclid Avenue, St. Louis, MO 63110.

a Present address: Department of Neurology, State University of New York, Stony Brook, NY 11794

'Present address: Division of Respiratory and Critical Care, Department of Medicine, Washington University School of Medicine, St. Louis, MO 63110

cPresent address: Molecular Neurobiology Laboratory, The Salk Institute, La Jolla, CA 92037.

Copyright (C) 1994 Society for Neuroscience $0270-6474 / 94 / 143500-11 \$ 05.00 / 0$
}

IKey words: cerebral cortex, development, extracellular matrix, chondroitin sulfate proteoglycans, axonal pathways, mouse, immunohistochemistry]

Axonal pathways are formed with great precision in the developing nervous system, providing a strong indication that the molecular guidance signals for axonal growth cones are distributed with similar spatial and temporal precision. Although none of these signals have been identified with certainty, it is likely that growth cones are guided by a combination of substratebound and diffusible factors that vary in different regions of their trajectory (Heffner et al., 1990; Jessell and Dodd, 1990; Lander, 1990; Bixby and Harris, 1991; Mason and Godement, 1991; Yaginuma and Oppenheim, 1991; Gotz et al., 1992; Kuwada, 1992). Substrate guidance is thought to be achieved through the restricted distribution of cell-surface, pericellular, and extracellular matrix molecules that permit or promote axonal elongation, together with components in adjacent regions that are either less favorable or inhibitory (Patterson, 1988; Snow et al., 1990; Keynes et al., 1991; Oakley and Tosney, 1991; Schwab et al., 1993; Steindler, 1993).

A variety of observations on axonal outgrowth in vitro provide evidence that components of the pericellular/extracellular matrix (ECM), including fibronectins, members of the laminin family, tenascin, thrombospondin, and certain proteoglycans promote neurite outgrowth alone and in combination (Bixhy and Harris, 1991; Reichardt and Tomaselli, 1991; Letourneau et al., 1992; Sanes, 1992), and thus are potential substrates for defining axonal pathways in vivo. Experimental evidence has also led to the suggestion that ECM components, most notably tenascin and chondroitin sulfate proteoglycans (CSPGs), may serve as inhibitory substrates or boundaries (Carbonetto et al., 1983; Verna et al., 1989; Snow et al., 1990; Steindler et al., 1990; Oakley and Tosney, 1991; Letourneau et al., 1992). Given the wide variety of potential guidance cues identified by cell culture methods, defining the spatiotemporal distribution of particular ECM components in relation to actual growth cone trajectories in the developing nervous system is a critical first step in determining which of these many components provide guidance in the formation of particular pathways.

The first studies on the distribution of ECM in the developing neocortex established that glycoconjugates, defined by histochemistry or lectin binding, are prominent in the preplate and its derivatives, the marginal zone and subplate (Nakanishi and Derer, 1982; Derer and Nakanishi, 1983; Nakanishi, 1983; Bruckner et al., 1985). More recently, immunohistochemistry 

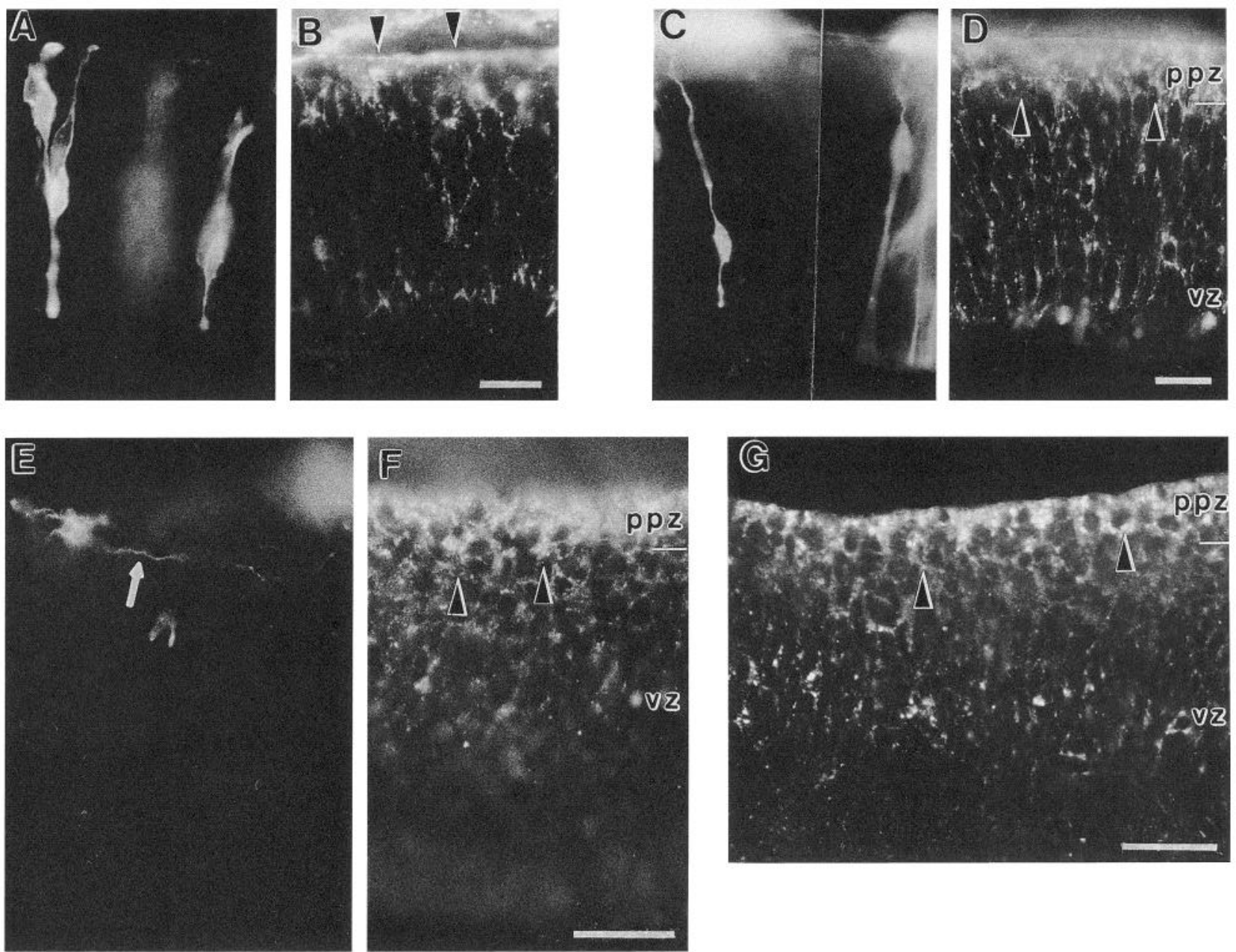

Figure 1. Changes in the distribution of immunolabeling for CSPGs accompany preplate formation. In each pair of photographs $(A$ and $B$; $C$ and $D ; E$ and $F$ ) DiI labeling is shown on the left and immunofluorescent labeling of the same field for CSPGs is shown on the right. $A$, Prior to preplate formation (E10), DiI-labeled cells of the neuroepithelium span the telencephalic wall. Their nuclei are at different levels, reflecting interkinetic nuclear migration. $B$, Immunolabeling for CSPGs is scattered throughout the neuroepithelium; a band of more intense labeling is associated with the pia-arachnoid (arrowheads). C, As the telencephalic wall becomes wider (E11), the long processes of cells within it, some of which are presumably radial glia, extend to the pial surface. $D$, As the first postmitotic neurons leave the ventricular zone to form the preplate zone, an increase in immunolabeling for CSPGs (arrowheads) becomes apparent in the early preplate. E. An early (E12) preplate neuron extends an axon (arrow) through the preplate into the nascent intermediate zone. $F$, Immunolabeling for CSPGs becomes more prominent in the preplate (arrowheads), but is partially obscured by the more intense labeling of the pia-arachnoid that is in a different plane and therefore out of focus. $G$, Preplate zone stage (E12); the pia-arachnoid has been removed to better demonstrate CSPG immunolabeling surrounding the cell bodies of preplate neurons (arrowheads). $p p z$, preplate zone; $v z$, ventricular zone. Scale bars: $B$ and $D, 25 \mu \mathrm{m} ; F$ and $G, 50 \mu \mathrm{m}$.

has been helpful in identifying these ECM components. Fibronectin (FN) is evident in the preplate and its derivatives, the marginal zone and subplate (Stewart and Pearlman, 1987; Chun and Shatz, 1988; Sheppard et al., 1991), where it is concentrated along the processes of radial glia (Sheppard et al., 1991). CSPGs are especially prominent in the preplate/marginal zone/subplate (Sheppard et al., 1991). This distribution leads to an apparent conflict between the observation that these layers contain many growing axons (Marin-Padilla, 1978; Crandall and Caviness, 1984; McConnell et al., 1989; Catalano et al., 1991; De Carlos and O'Leary, 1992; Miller et al., 1993) and the suggestion that sulfated glycosaminoglycans serve as barriers to axon outgrowth in other locations (Snow et al., 1990; Oakley and Tosney, 1991; Steindler, 1993).

The present study was undertaken to determine the spatial relationship of forming efferent and afferent axonal pathways in the developing neocortex to the changing distribution of
CSPGs. We used a fluorescent lipophilic carbocyanine dye (DiI) to define axonal trajectories in the fixed brains of embryonic mice (Honig and Hume, 1986; Godement et al., 1987), and immunolabeling with a monoclonal antibody to the glycosaminoglycan side chains of CSPGs (Avnur and Geiger, 1984) to define their distribution. We find that the relationships of efferent and afferent axons to CSPGs differ, suggesting a role for these proteoglycans in axon segregation. CSPGs do not appear to provide a barrier to outgrowth for either axonal class, but instead may help to define the cortical pathway of afferent thalamic axons.

A preliminary report of this work has been presented (Bicknese et al., 1991).

\section{Materials and Methods}

Fixation. Timed pregnancies were produced by $24 \mathrm{hr}$ matings of C57Bl/ $6 \mathrm{~J}$ mice (Jackson Laboratories, Bar Harbor, ME). The day of conception 

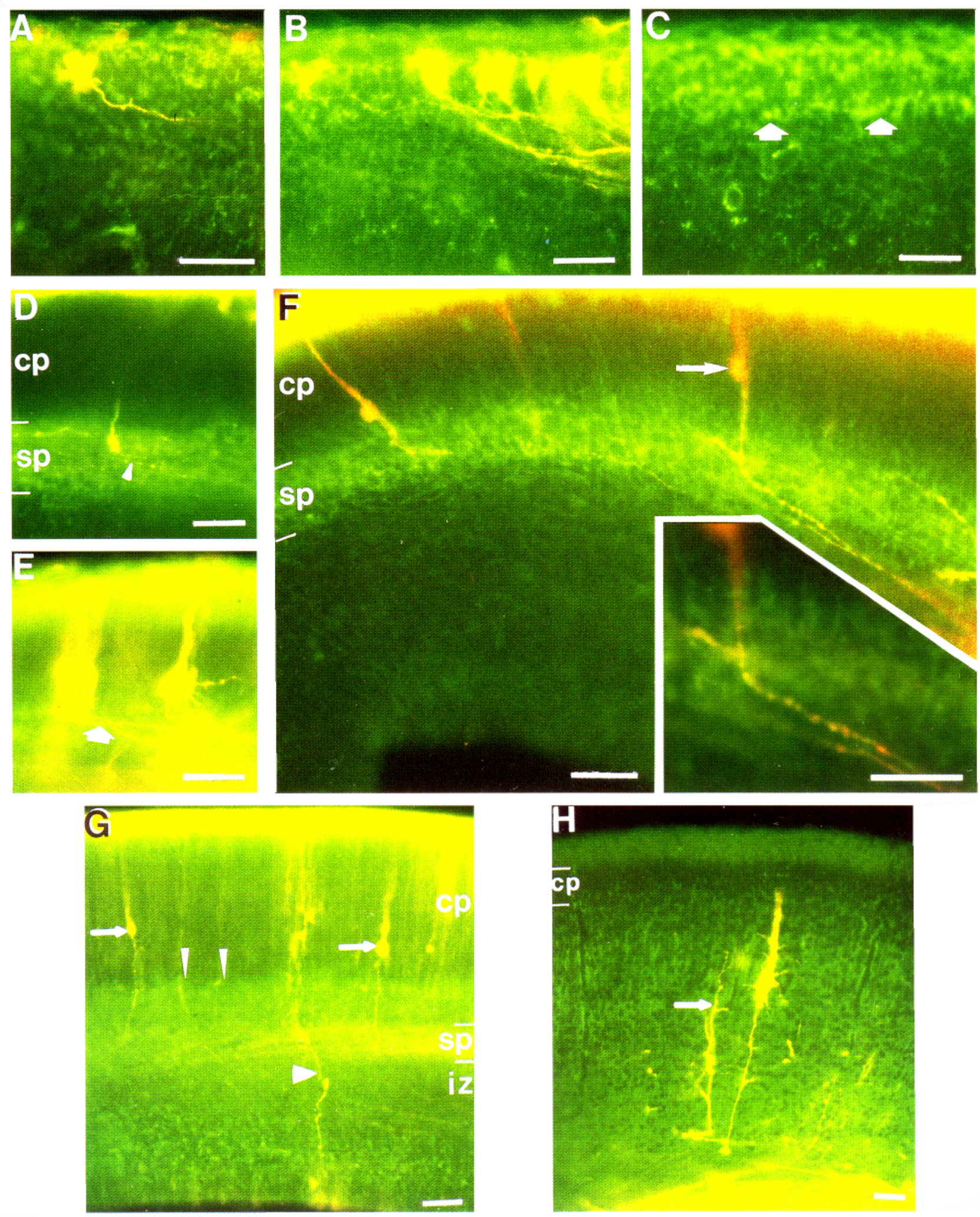

Figure 2. Axons of cortical neurons travel across CSPG-rich zones; the relationship of these axons to CSPGs varies with the location of the neuronal cell body. Photographic double exposures of coronal sections demonstrate the relationship of Dil-labeled neurons (yellow or red-orange) to immunolabeling for CSPGs (green). A, The axon of an early preplate neuron leaves the CSPG-rich preplate obliquely (E12; cortical DiI placement). $B$, The axons of more mature, polarized preplate cells extend out of the preplate at varying angles, leaving the preplate either directly or more gradually. $C$, Single exposure of the immunolabeling for CSPGs (same area as shown in the double exposure of $B$ ), emphasizing the collection of CSPGs (arrows) just below these cells that is an early manifestation of cortical plate formation (E13; cortical DiI placement). D, Subplate cell extending a fine axon (arrowhead) that traverses the CSPG-rich subplate obliquely (E15; cortical DiI placement). E, Neurons in the lower cortical plate/upper subplate retrogradely labeled by thalamic DiI placement. Neurons with cell bodies close to the CSPG-rich subplate extend axons (arrow) that traverse the subplate at varying angles (E14 cortex; thalamic DiI placement). $F$, Neuron within the cortical plate (arrow) extends an axon that 


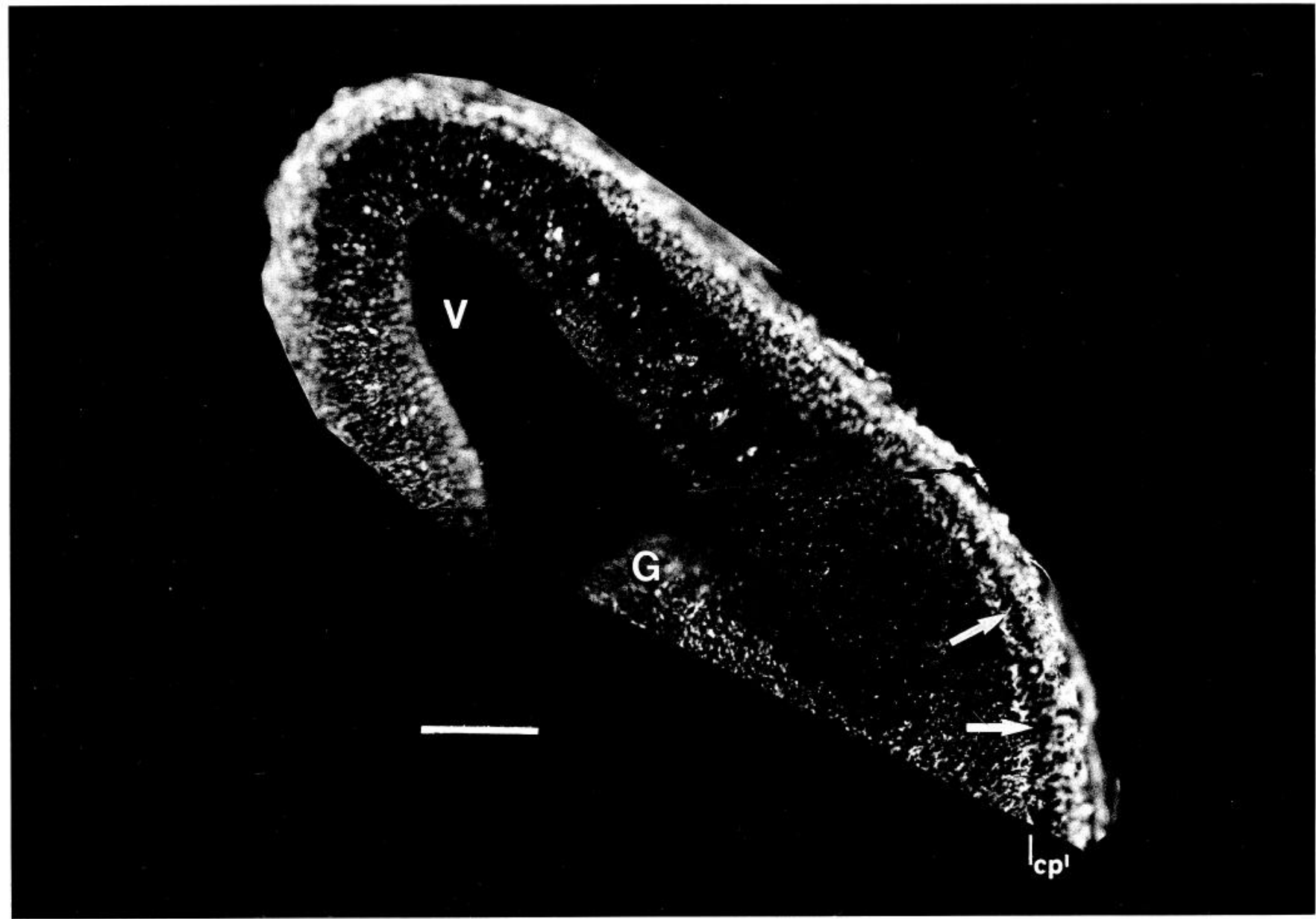

Figure 3. Cortical plate formation divides the preplate and its associated CSPGs. Photomontage of a coronal section of the telencephalic wall (E13), immunolabeled for CSPGs, demonstrates the maturational gradient extending from ventrolateral (right side of figure) to dorsomedial (left side of figure). Immunolabeling for CSPGs is prominent in the preplate dorsomedially; the preplate is split in the more mature cortex ventrolaterally by the forming cortical plate ( $c p$, arrows) into the marginal zone above and the subplate below. $G$, ganglionic eminence; $V$, lateral ventricle. Scale bar, $100 \mu \mathrm{m}$.

was designated embryonic day 0 (E0). From E10 to E14, pregnant females were killed with carbon dioxide, and the embryonic heads were fixed by immersion in $4 \%$ paraformaldehyde in PBS (pH 7.5) for 12 $20 \mathrm{hr}$, and then transferred to PBS with $0.2 \%$ sodium azide until sectioned. From E15 to E17, pregnant females were anesthetized with intraperitoneal chloral hydrate $(3.5 \%, 0.1 \mathrm{cc} / 10 \mathrm{gm}$ body weight). Embryos were removed individually and perfused with $2-3 \mathrm{ml}$ of $4 \%$ paraformaldehyde in PBS. The heads were postfixed in the same fixative for $18-20 \mathrm{hr}$, and then treated as above. A few embryos that were used for immunolabeling only were fixed by immersion or perfusion as above, placed in $30 \%$ sucrose in PBS overnight without postfixation, and then frozen.

DiI placement. The fluorescent lipophilic dye 1, $1^{\prime}$-dioctocecyl-3,3,3'tetramethylindocarbocyanine perchlorate (DiI; Molecular Probes) was used as an anterograde and retrograde tracer (Honig and Hume, 1989). Four methods of DiI placement were used. (1) Small crystals of DiI were placed in either the cortex or the thalamus of fixed embryos with a fine tungsten microelectrode. (2) In a few cases, glass micropipettes were immersed in a solution of DiI in ethyl alcohol. The alcohol was evaporated, leaving fine crystals of DiI on the probes that were then inserted in thalamus or cortex (Bhide and Frost, 1991). (3) DiI was dissolved in dimethylformamine $(0.1-1 \%$ by weight). Glass micropipettes were dipped into the solution, and then touched to the cortex or inserted into selected regions of the thalamus. The more dilute solutions were used for cortical placements. (4) DiI was dissolved in $100 \%$ ethyl alcohol ( $1 \%$ by weight) and the suspension injected into the ventricular system in E10-E12 embryos to label cells of the ventricular zone. After DiI placements, embryonic brains were stored at room temperature for variable minimum periods to allow dye diffusion: E10, 7 d; E11-E14, 3 weeks; E15-E16, 5 weeks; E17, 8 weeks.

Immunolabeling. DiI-labeled brains were sectioned coronally with a vibratome (70-80 $\mu \mathrm{m}$; Oxford Instruments). Frozen brains were sectioned on a cryostat (30 $\mu \mathrm{m}$; Hacker Instruments). The methods for immunolabeling frozen sections have been described previously (Stewart and Pearlman, 1987; Sheppard et al., 1991). These methods were modified for application to vibratome sections. Floating vibratome sections were immunolabeled in wells. A monoclonal antibody (CS-56, $1: 500$; Sigma) to the glycosaminoglycan side chains of chondroitin sul-

traverses the CSPG-rich subplate directly, and then turns abruptly to run in the upper intermediate zone. Inset, Higher magnification of the abrupt turn of the cortical plate axon at the lower border of the CSPG-rich subplate (E15: cortical DiI placement). $G$, Cortical plate neurons (arrows) and a long radial glial process (thick arrowhead) labeled by DiI. Immunolabeling for CSPG continues to be intense within the subplate, and is also beginning to be apparent in the lower cortical plate (thin arrowheads) and intermediate zone (E16; cortical DiI placement). $H$, Pyramidal cell in cortex next to a thalamic afferent (arrow). Immunolabeling for CSPGs involves much of the differentiating cortex, but not the remnant of dense cortical plate just below the marginal zone (E18; thalamic DiI placement). $c p$, cortical plate; $i z$, intermediate zone; $s p$, subplate; $v z$, ventricular zone. Scale bars, $50 \mu \mathrm{m}$. 
fate proteoglycans (Avnur and Geiger, 1984) was applied overnight at $4^{\circ} \mathrm{C}$ with gentle agitation of floating sections. Secondary labeling was with a goat antiserum against mouse IgM tagged with fluorescein (1: 200; Jackson Immunochemicals) applied for $2 \mathrm{hr}$ at room temperature Sections were mounted on subbed slides and coverslipped with $0.01 \%$ $p$-phenylenediamine (Sigma) in glycerin (Johnson and Nogueira-Araujo, 1981), and then viewed with epifluorescence microscopy.

\section{Results}

To facilitate the description of the relationship of DiI-labeled axons to the distribution of CSPGs, we have delimited several stages of cortical development that are named for their major morphological features (Stewart and Pearlman, 1987; Sheppard et al., 1991). The first neurons to be generated in the embryonic cortex leave the ventricular zone to form the preplate (Rickmann et al., 1977), also termed the primordial plexiform zone (MarinPadilla, 1971), just beneath the pia. The preplate is divided into the marginal zone above and the subplate below by the insertion of cortical plate neurons that will form layers II-VI of the mature cortex (Marin-Padilla, 1971; Raedler and Raedler, 1978; Luskin and Shatz, 1985; Bayer and Altman, 1991; Wood et al., 1992). The embryonic ages provided for these stages are approximate; since there are pronounced ventrolateral-to-dorsomedial and anterior-to-posterior cortical developmental gradients (Smart and Smart, 1982; Bayer and Altman, 1991), more than one stage is usually evident in sections at a given embryonic age, depending on the location within the telencephalic wall.

\section{Ventricular zone and preplate stages}

Prior to preplate formation (E10), intracortical or ventricular placements of DiI demonstrate the radially oriented neuroepithelial cells that span the telencephalic wall, but no cells with the morphology of postmitotic neurons are evident (Fig. 1 $A$ ). Scattered faint immunolabeling for CSPGs is present throughout the ventricular zone; a band of intense labeling is evident in association with the pia-arachnoid (Fig. 1B).

As the first postmitotic neurons form the preplate (E11 to early E13), immunolabeling for CSPGs becomes intense around these cells (Fig. $1 D, F, G$ ). DiI placements in the cortex disclose very early preplate neurons that are extending processes as the preplate forms (Fig. $1 E$ ) as well as elongated cells in the ventricular zone, some of which are presumably radial glia (Fig. $1 C$ ). The early neurons have rounded cell bodies and several short processes confined to the preplate; some have an axon that leaves the zone of heaviest CSPG labeling in the preplate to extend ventrolaterally within the upper ventricular zone (Figs. $1 E, 2 A)$. In the late preplate stage, the cell bodies of many preplate neurons have become elongated and more polarized. They have dendrites that extend laterally or toward the pial surface and an axon that arises near the lower end of the cell body and extends into the forming intermediate zone (Fig. 2B), which contains considerably less immunolabeling for CSPGs than the preplate (Figs. $1 F, G ; 2 A, B$ ). At this stage the growth cones of the most mature preplate/subplate cells have reached the ventrolateral aspect of the telencephalic vesicle, and are about to enter the region that will become the internal capsule (data not shown).

\section{Early cortical plate stage}

Immunolabeling for CSPGs provides one of the earliest indications of cortical plate formation within the preplate (late E12E13). A line of intense CSPG immunolabeling forms just below the cell bodies of the preplate neurons (Fig. 2B,C). As this ap- pears, the preplate is split by the forming cortical plate, which has very little immunoreactivity for CSPGs (Fig. 3, arrows); immunolabeling continues to be associated with the preplate cells as they form the subplate and marginal zone (Fig. 3). Formation of the cortical plate within the preplate proceeds along cortical maturational gradients, beginning first in the ventrolateral wall of the telencephalic vesicle and extending dorsomedially (Fig. 3). A similar gradient in cortical maturation occurs in the rostrocaudal axis (not shown).

Axons of marginal zone and subplate neurons have different courses, even though both cell types were formcrly in the prcplate. Marginal zone neurons extend processes within the marginal zone, eventually forming an elaborate network that is restricted to that layer (not illustrated). The axons of many subplate neurons leave the intensely immunolabeled subplate almost immediately and continue along a tangential trajectory within the intermediate zone, which contains much less CSPG. Axons of more superficial subplate neurons often course obliquely through the subplate toward the intermediate zone (Fig. $2 D$ ). The course taken by efferent axons arising from cells in the cortical plate differs depending on the location of the cell body in relation to the subplate and its associated CSPGs. Neurons in the lower cortical plate with cell bodies adjacent to the subplate and its associated CSPGs extend axons that traverse the subplate obliquely for variable distances before entering the intermediate zone (Fig. 2E). In contrast, neurons with cell bodies that are higher up in the cortical plate and thus not in contact with the subplate extend axons perpendicular to the pia that travel directly downward through the cortical plate and subplate. Once across the subplate, these axons turn abruptly to extend ventrolaterally in the upper intermediate zone, toward the forming internal capsule (Fig. $2 F$ and inset).

At approximately the stage (E14) when the cortical plate has formed across the cntirc dorsolateral wall of the telencephalic vesicle, axons of the most mature subplate and cortical plate neurons, which are in the ventrolateral wall of the telencephalon, have begun to reach the thalamus (not illustrated). Slightly later (late E14), another class of cortical neurons, with axons that project medially, becomes evident. Medially projecting axons from neurons in the subplate and cortical plate extend downward into the intermediate zone, and then turn to project medially (Fig. 4), often descending farther into the intermediate zone in stepwise fashion. Many of the axons from medially projecting cortical plate neurons will eventually enter the corpus callosum and project to targets in the contralateral hemisphere (not illustrated).

\section{Arrival of thalamocortical axons}

Axons arising from neurons in the thalamus pass through the internal capsule, and then enter the lateral wall of the telencephalic vesicle in a broad front at approximately the stage when the first cortical efferents reach the thalamus (E14). Once within the neocortex the pathway of thalamocortical axons is centered on the CSPG-rich subplate; their trajectory quickly narrows as they traverse the intermediate zone to grow toward and then into the subplate (Fig. $5 A-C$ ). The complex growth cones of the lcading afferent axons are always found within the subplate (Fig. $5 B$ ). Thalamocortical afferents extend for long distances through the CSPG-rich subplate (Fig. 5A), and are thus segregated from the axons of both subplate and cortical plate neurons that have descended through the subplate and are extending ventrolaterally in the intermediate zone toward the internal capsule. Later- 
arriving axons appear to fasciculate with their predecessors within the subplate. Many thalamocortical axons have collateral branches that extend upward toward the cortical plate (E15; Fig. $5 E$ ). In the more mature areas of the lateral wall, these collaterals reach into the lower cortical plate (early E16; Fig. $5 C$ ). Slightly later (E16 and early E17), the leading thalamocortical axons have extended along the subplate completely around to the dorsomedial aspect of the telencephalic hemisphere.

\section{Late cortical plate stage and early cortical differentiation (E16-P1)}

The distribution of CSPGs becomes more widespread as the cell-dense cortical plate matures to form laminated neocortex along an inside-out gradient. Beginning in the ventrolateral cortical wall, diffuse immunolabeling for CSPGs becomes apparent above the subplate as the most mature cortical plate cells form layer VI (Fig. 2G) and collateral branches of thalamocortical axons extend upward into differentiating cortex (Fig. $5 C-E$ ), but remains sparse in the dense cortical plate. Faint immunolabeling is also evident in the lower intermediate zone (Fig. 2G). Immunolabeling gradually extends upward as cortical plate cells mature and thalamic axons extend farther into the differentiating cortex (Fig. $2 \mathrm{H}$ ).

\section{Discussion}

The pathway followed by axons leaving the developing neocortex of the mouse is distinct from the adjacent pathway taken by afferents arriving from the thalamus. These two axonal trajectories also differ in their relationship to the CSPGs that are a major component of the ECM of developing cortex (Fig. 6). Although efferent axons from neurons in the subplate and cortical plate have different courses, they all cross the CSPG-rich preplate/subplate to extend in the intermediate zone, which contains much less CSPG (Fig. 6). In contrast, the thalamocortical afferents travel within the CSPG-rich subplate once they reach the ventrolateral telencephalic wall (Fig. 6). Thus, CSPGs do not appear to form a barrier to axonal extension for either of these major axonal tracts. Instead, the distribution of CSPGs supports a role in the segregation of afferent and efferent pathways within the cortex, and in the definition of the thalamocortical pathway.

\section{A potential role for CSPGs in the segregation of axons leaving and entering the neocortex}

We postulate that the marked difference in the abundance of CSPGs between the thalamocortical afferent pathway and that taken by neocortical efferents within the cortical wall is a molecular distinction that contributes to the segregation of these axonal systems. In this formulation, CSPGs, in combination with the other ECM components present in the subplate (summarized in Stewart and Pearlman, 1987; Sheppard et al., 1991) would serve as the preferred substrate for thalamocortical afferents, but not for cortical efferents. Preplate/subplate neurons are closely associated with these ECM components, which include fibronectin (Stewart and Pearlman, 1987; Chun and Shatz, 1988; Sheppard et al., 1991). Although these neurons do not appear to produce fibronectin (Pearlman et al., 1992), the prospect remains that they may produce CSPGs, and could serve an important role in ECM assembly.

The relationship of neocortical efferents to CSPGs. The first efferents to leave the developing neocortex of the mouse arise from cells in the preplate; axons of cortical plate neurons depart

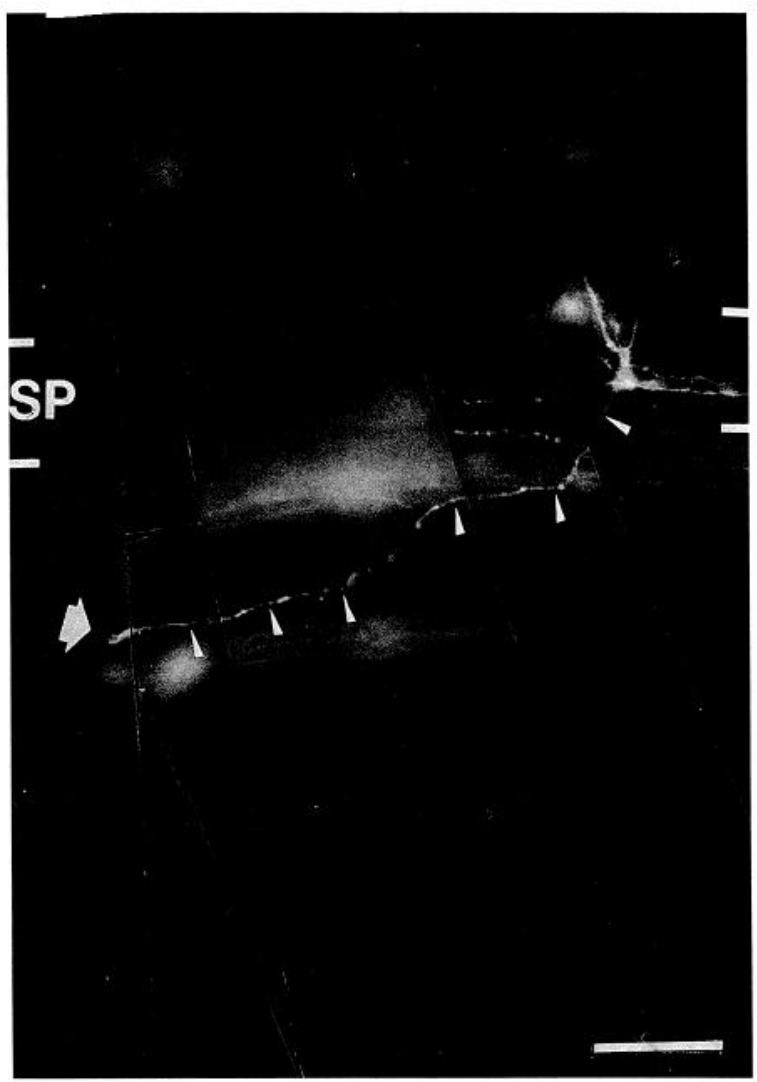

Figure 4. A subset of subplate and cortical plate neurons projects medially. Photomontage of a DiI-labeled subplate neuron shows the axon (arrowheads) extending medially (toward the left) as it descends into the lower intermediate zone in a stepwise manner. The growth cone is indicated by an arrow. $s p$, subplate. Scale bar, $50 \mu \mathrm{m}$.

soon thereafter. These observations confirm findings in the cat (McConnell et al., 1989) and rat (De Carlos and O'Leary, 1992; Erzurumlu and Jhaveri, 1992). Axons of preplate/subplate neurons arise in a CSPG-rich environment and continue to grow in it for variable distances, while axons from cortical plate neurons grow across the CSPG-rich subplate quite effectively, indicating that CSPGs do not constitute a barrier to either axon initiation or outgrowth. The differences between neocortex and other parts of the developing nervous system in this regard will be discussed below. If migrating cortical neurons were to extend their axons before they entered the cortical plate, as has been suggested by electron microscopic reconstructions (Shoukimas and Hinds, 1978) and by retrograde labeling combined with tritiated thymidine birthdating (Schwartz et al., 1991), they would not interact with substrate cues in the subplate. However, subsequent analysis with lipophilic dyes makes this unlikely; we have seen no indication of this phenomenon, and it has not been reported in several other studies (McConnell et al., 1989; Hernit et al., 1990; De Carlos and O'Leary, 1992; Erzurumlu and Jhaveri, 1992). After crossing the subplate, neocortical efferents destined for the internal capsule turn abruptly and continue in the intermediate zone, suggesting that they have found a more desirable substrate. To date there have been no reports demonstrating that potential substrate molecules are differentially distributed in the intermediate zone.

Medially projecting cortical plate cells, many of which will send axons through the corpus callosum (Koester and O'Leary, 

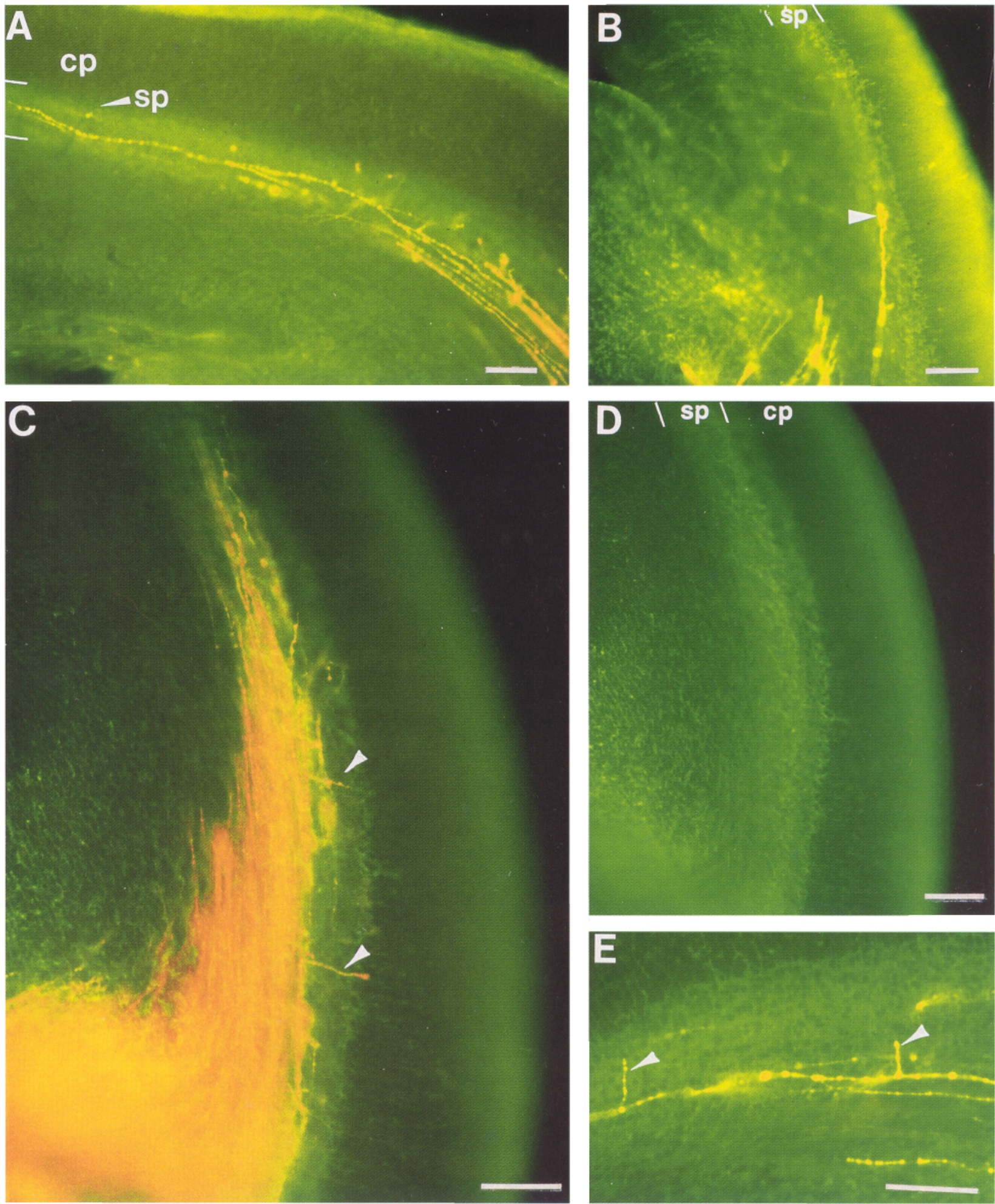

Figure 5. Thalamocortical afferent axons grow into and then along the CSPG-rich subplate. Photographic double exposures of coronal sections demonstrate the relationship of DiI-labeled thalamocortical axons (yellow or red-orange) to immunolabeling for CSPGs (green). DiI placements are in the thalamus. $A$, Thalamic afferents selectively extend within the CSPG-rich subplate for long distances (E16). $B$, Complex growth cone of a very early (E14) thalamic axon extending into the cortical subplate at the ventrolateral aspect of the telencephalic vesicle (arrowhead). $C$, Thalamic afferents in the ventrolateral aspect of the telencephalic vesicle grow toward and then into the cortical subplate. Early collateral branches are extending through the subplate (arrowheads) into the lower cortical plate (E15). D. Single exposure of immunolabeling for CSPGs (same field as $C$ ) to illustrate the intense labeling within the subplate that is obscured by DiI in the double exposure. E, Two collateral branches (arrowheads) extend from interstitial nodes of a single thalamic axon in the subplate (E16). $c p$, cortical plate; $s p$, subplate. Scale bars, $100 \mu \mathrm{m}$ 


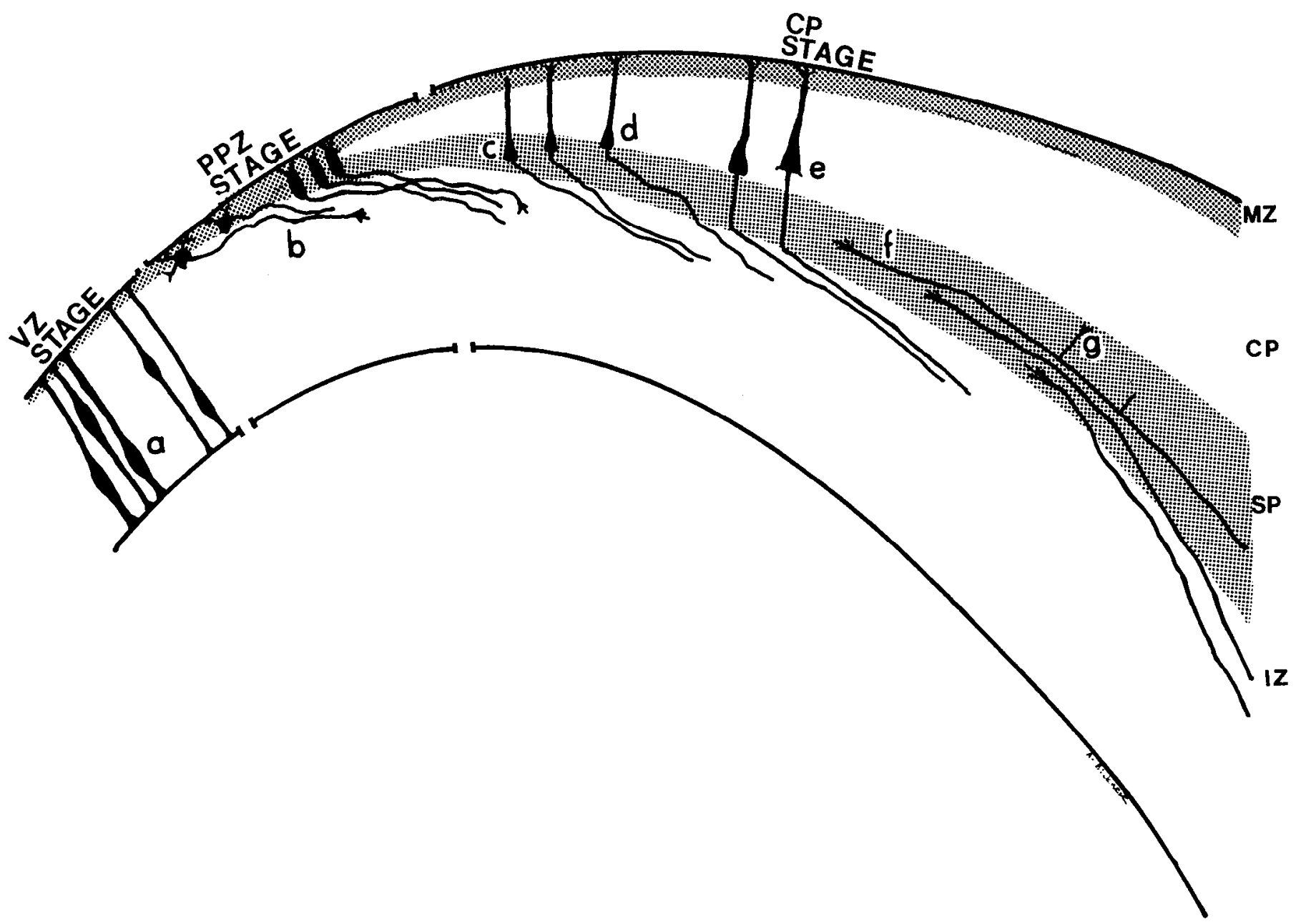

Figure 6. Schematic representation of the course of early neocortical efferent and afferent axons in relation to the distribution of CSPGs. The drawing shows the dorsolateral wall of the telencephalic vesicle of the mouse in an idealized coronal section approximately midway between the anterior and posterior poles of the hemisphere. For convenience, three stages of early cortical development are all represented in the same drawing; this compression is indicated by the broken lines at the pial (upper) and ventricular (lower) borders of the drawing. Prominent immunolabeling for CSPGs is indicated by shading. In the ventricular zone $(V Z)$ stage, processes of dividing cells $(a)$ and presumptive radial glia extend from pial to ventricular surfaces. In the preplate zone (PPZ) stage, CSPGs accumulate in the preplate as it is formed by the first postmitotic neurons. Axons of preplate neurons $(b)$, the first to leave the cortex, leave the preplate to run ventrolaterally in the upper ventricular zone, which will become the intermediate zone as more axons accumulate. The preplate neurons and their associated (SPGs are divided by formation of the cortical plate (CP) to form the subplate $(S P)$ below the cortical plate and the cell-sparse marginal zone $(M Z)$ above the cortical plate. Efferent axons from neurons in the subplate $(c)$ and from those in the cortical plate that are close to the subplate $(d)$ traverse the CSPG-rich subplate diagonally or more directly to enter the intermediate zone $(I Z)$. Axons from neurons higher in the cortical plate $(e)$ traverse the subplate directly, and then turn abruptly to run ventrolaterally in the intermediate zone. In contrast, the first afferent axons $(f)$, which arrive from the thalamus, enter the CSPG-rich subplate and travel within it. Collateral branches $(g)$ of these axons enter the cortical plate.

1993; present study), have more variable courses than cortical plate cells projecting laterally toward the internal capsule. Many travel along the subplatc for short distances before descending into the intermediate zone, where they make intermittent stepwise shifts to lower levels. This appearance suggests that they may be following substrate cues on the surface of other axons, with little or no regard for the distribution of CSPGs.

The relationship of thalamocortical afferents to CSPGs. The first axons to arrive in the developing cortex come from the thalamus, and not from midbrain monodminergic nuclei or other locations (De Carlos and O'Leary, 1992; Erzurumlu and Jhaveri, 1992). Thalamocortical afferents arrive in the CSPG-rich subplate well after the early efferents have departed and the cortical plate has been established (McConnell et al., 1989; De Carlos and O'Leary, 1992; Erzurumlu and Jhaveri, 1992; Miller et al., 1993; present study). After extending along the subplate for varying distances they extend collateral branches into the maturing decp layers of the cortcx. Two indicators of early cortical maturation occur at very nearly the same time as these collateral branches extend upward: (1) the distance between neuronal cell bodies increases in the deepest aspect of the cell-dense cortical plate as the neuropil expands, and (2) immunoreactivity for CSPGs becomes evident in these maturing layers. CSPG expression continues to accompany the upward progress of maturation of the cell-dense cortical plate, which contains very little CSPG. This finding differs from an earlier observation from this laboratory (Sheppard et al., 1991) indicating that immunolabeling for CSPGs is not present in cortex during its early maturation. We consider the present observation to be correct, and attribute the difference to improvements in methodology that 
have increased the sensitivity of the immunolabeling. That the expression of CSPGs in maturing cortex coincides with the invasion of axon collaterals further indicates that CSPGs do not constitute a barrier for these processes, and may instead be involved in promoting their growth from the subplate into the cortical plate.

The targeting of thalamocortical afferents to specific cortical areas is precise from the outset, indicating that there may be cues to this specificity in the subplate (De Carlos et al., 1992; Miller et al., 1993). Ablation studies demonstrate that thalamocortical connections are not established when the underlying subplate has been destroyed (Ghosh and Shatz, 1993), and that the formation of the restricted connections within the cortex that underlie ocular dominance columns is also disrupted (Ghosh and Shatz, 1992). CSPGs in the subplate are not likely to be involved in the specification of areal connections, or in establishing a concentration gradient to guide growing axons, since they appear to be uniformly distributed along the entire subplate when analyzed with the antibody to chondroitin sulfate side chains that we used in these studies. However, as discussed below, differences in the structure of proteoglycan core proteins or the arrangement of glycosaminoglycan side chains would not be detectable with this antibody. It remains to be determined whether such distinctions are present in the subplate.

The distinction between efferent and afferent pathways that we have demonstrated in the embryonic cortex provides a developmental basis for the separation of these two pathways in the white matter of adult cortex (Woodward and Coull. 1984; Woodward et al., 1990). This segregation of afferent and efferent pathways in the cortical wall does not support the suggestion (Blakemore and Molnar, 1990) that efferents from a given cortical area are guiding specific thalamic afferents to their appropriate cortical targets. Cortical efferents and thalamic afferents initially meet in the nascent internal capsule at the level of the striatum, but they interdigitate for relatively short distances (Bicknese and Pearlman, 1992; De Carlos and O'Leary, 1992; Erzurumlu and Jhaveri, 1992; Miller et al., 1993). The present analysis of axonal trajectory in relation to CSPGs is limited to the intracortical portion of these pathways; their relationship in the forming internal capsule is the subject of a study currently in progress (Bicknese and Pearlman, 1992).

\section{CSPGs as substrates or barriers}

The presence of barriers to axon outgrowth in vivo, inferred when axons turn to avoid a given region or remain in a pathway and do not invade adjacent territory (Oakley and Tosney, 1991), has been confirmed by experimental ablations and transplantations (Tosney and Landmesser, 1984; Tosney, 1988; Tosney and Oakley, 1990). In the chick embryo, tissues outside the spinal cord that are barriers to motor axons immunolabel with antibodies to chondroitin-6-sulfates and bind peanut agglutinin, whereas the pathways taken by motor axons do not (Tosney and Landmesser, 1985; Tosney and Oakley, 1990; Keynes et al., 1991; Oakley and Tosney, 1991). In addition, axons entering the spinal cord from dorsal root ganglia turn to avoid the roof plate, which contains keratin sulfates (Snow et al., 1990; Cole and McCabe, 1991) as well as chondroitin-6-sulfates and the peanut agglutinin ligand (Oakley and Tosney, 1991). However, these same markers are also evident in a pathway for spinal commissural axons, indicating that they may be barrier molecules only for particular axonal types (Oakley and Tosney, 1991; Yaginuma and Oppenheim, 1991). Retinal axons grow toward the central retina in conjunction with a central-to-peripheral graded decline in the expression of CSPGs, suggesting that CSPGs may contribute to directional growth by an inhibitory mechanism (Snow et al., 1991; Brittis et al., 1992).

Experimental evidence from tissue culture assays is consistent with the suggestion that some proteoglycans may be nonpermissive or inhibitory (Carbonetto et al., 1983; Verna et al., 1989; Snow et al., 1990; Cole and McCabe, 1991; McKeon et al., 1991; Letourneau et al., 1992; Geisert and Bidanset, 1993), but tissue culture assays have also indicated that neurite outgrowth is supported or promoted by both the core proteins and the glycosaminoglycan side chains of proteoglycans (lijima et al., 1991; Lafont et al., 1992).

There are several possible explanations for the differences between our observations and those indicating that CSPGs act as inhibitory or barrier molecules. (1) The roles of CSPGs may differ from one site to another as a result of their association with other ECM molecules. For example, the nonpermissive activity of chondroitin sulfates for the outgrowth of neurites from several types of cultured neurons can be modified as a function of their concentration relative to laminin (Snow et al., 1990; Snow and Letourneau, 1992). (2) CSPGs differ considerably in the structure of their core proteins and in the number and size of their glycosaminoglycan side chains, and thus are functionally diverse as well (Gallagher, 1989). They have been shown to either enhance or hinder the attachment of cell-surface receptors to other ECM components, depending on the structure of the proteoglycan and the test system under study (Gallagher, 1989; Letourneau et al., 1992). In addition, embryonic and mature forms of a given proteoglycan may differ considerably (Rauch et al., 1992). (3) Different axonal populations may respond differently to the same proteoglycans (Iijima et al., 1991; Oohira et al., 1991). Our observations suggest that afferent and efferent growth cones respond differentially to the CSPGs that are enriched in the subplate, although neither type is inhibited. Axons growing into or out of the spinal cord might be inhibited by the CSPGs that appear to be barriers in these locations (Tosney and Landmesser, 1985; Snow et al., 1990; Tosney and Oakley, 1990; Oakley and Tosney, 1991; Pindzola et al., 1993), even if they are the same CSPGs as those in the developing cortex.

The clear distinctions in the relationship of different sets of growing axons to CSPGs underlines the importance of defining the molecular specificity of individual axonal pathways. This will require both the identification of potential substrate components in the developing brain and their spatiotemporal localization. The wide variability of proteoglycan structure, together with their ability to bind trophic factors and interact with other matrix molecules and with cell adhesion molecules (Ruoslahti, 1989; Rauch et al., 1992; Grumet et al., 1993), makes them particularly interesting candidates for roles in axon guidance. Biochemical evidence indicates that a large number of proteoglycans are present in the developing brain (Oohira et al., 1988; Herndon and Lander, 1990; Zaremba et al., 1990). The genes for several proteoglycan core proteins have recently been identified and sequenced (Ruoslahti, 1989), including some that are specific to the nervous system (Rauch et al., 1991, 1992). Our preliminary results indicate that one of these CSPGs, ncurocan (Rauch et al., 1992), is prominent in the preplate/subplate as the first efferent and afferent axons extend (Miller et al., 1992). Information on the structure of the proteoglycans present in the developing nervous system at specific times and locations will make it possible to determine whether the proteoglycans present 
in axonal pathways and in putative barrier regions are structurally distinct, and then allow for direct experimental tests of their functional role.

\section{References}

Avnur Z, Geiger B (1984) Immunocytochemical localization of native chondroitin-sulfate in tissues and cultured cells using specific monoclonal antibody. Cell 38:811-822.

Bayer SA, Altman J (1991) Neocortical development. New York: Raven.

Bhide PG, Frost DO (1991) Stages of growth of hamster retinofugal axons: implications for developing axonal pathways with multiple targets. J Neurosci 11:485-504.

Bicknese AR, Pearlman AL (1992) Growing corticothalamic and thalamocortical axons interdigitate in a restricted portion of the forming internal capsule. Soc Neurosci Abstr 18:778.

Bicknese AR, Sheppard AM, O'Leary DDM, Pearlman AL (1991) Thalamocortical axons preferentially extend along a chondroitin sulfate proteoglycan-enriched pathway coincident with the neocortical subplate and distinct from the efferent path. Soc Neurosci Abstr 17: 764.

Bixby JL, Harris LA (1991) Molecular mechanisms of axonal growth and guidance. Annu Rev Cell Biol 7:117-159.

Blakemore C, Molnar Z (1990) Factors involved in the establishment of specific interconnections between thalamus and cerebral cortex. Cold Spring Harbor Symp Quant Biol 55:491-504.

Brittis PA, Canning DR, Silver J (1992) Chondroitin sulfate as a regulator of neuronal patterning in the retina. Science 255:733-736.

Bruckner G, Muller L, Wollweber L, Samtleben R, Biesold D (1985) Lectin binding sites and anionic components related to differentiation in the prenatal rat cerebral cortex. J Hirnforsch 6:615-634.

Carbonetto S, Gruver MM, Turner DC (1983) Nerve fiber growth in culture on fibronectin, collagen, and glycosaminoglycan substrates. J Neurosci 3:2324-2335.

Catalano SM, Robertson RT, Killackey HP (1991) Early ingrowth of thalamocortical afferents to the neocortex of the prenatal rat. Proc Natl Acad Sci USA 88:2999-3003.

Chun JJM, Shatz CJ (1988) A fibronectin-like molecule is present in the developing cal cerebral cortex and is correlated with subplate neurons. J Cell Biol 106:857-872.

Cole GJ, McCabe CF (1991) Identification of a developmentally regulated keratin sulfate proteoglycan that inhibits cell adhesion and neurite outgrowth. Neuron 7:1007-1018.

Crandall JE, Caviness VS Jr (1984) Axon strata of the cerebral wall in embryonic mice. Dev Brain Res 14:185-195.

De Carlos JA, O'Leary DDM (1992) Growth and targeting of subplate axons and establishment of major cortical pathways. J Neurosci 12: 1194-1211.

De Carlos JA, Schlaggar BL, O'Leary DDM (1992) Targeting specificity of primary sensory thalamocortical axons in developing rat cortex. Soc Neurosci Abstr 18:57.

Derer P, Nakanishi S (1983) Extracellular matrix distribution during neocortical wall ontogenesis in "normal" and "reeler" mice. J Hirnforsch 24:209-224.

Erzurumlu RS, Jhaveri S (1992) Emergence of connectivity in the embryonic rat parietal cortex. Cereb Cortex 2:336-352.

Gallagher JT (1989) The extended family of proteoglycans: social residents of the pericellular zone. Curr Opin Cell Biol 1:1201-1218.

Geisert EE, Bidanset DJ (1993) A central nervous system keratan sulfate proteoglycan: localization to boundaries in the neonatal rat brain. Dev Brain Res 75:163-173.

Ghosh A, Shatz CJ (1992) Involvement of subplate neurons in the formation of ocular dominance columns. Science 255:1441-1443.

Ghosh A, Shatz CJ (1993) A role for subplate neurons in the patterning of connections from thalamus to neocortex. Development 117:10311047.

Godement P, Vanselow J, Thanos S, Bonhoeffer F (1987) A study in developing nervous systems with a new method of staining neurones and their processes in fixed tissue. Development 101:697-713.

Gotz M, Novak N, Bastmeyer M, Bolz J (1992) Membrane bound molecules in rat cerebral cortex regulate thalamic innervation. Development 116:507-519.

Grumet M, Flaccus A, Margolis RU (1993) Functional characteriza- tion of chondroitin sulfate proteoglycans of brain: interactions with neurons and neural cell adhesion molecules. J Cell Biol 120:815-824.

Heffner CD, Lumsden AGS, O'Leary DDM (1990) Target control of collateral extension and directional axon growth in the mammalian brain. Science 247:217-220.

Herndon ME, Lander AD (1990) A diverse set of developmentally regulated proteoglycans is expressed in the rat central nervous system. Neuron 4:949-961.

Hernit CS, Van Sluyters RC, Murphy KM (1990) Visual callosal development in neonatal rats: do migrating or undifferentiated cells have interhemispheric axons? Soc Neurosci Abstr 16:803.

Honig MG, Hume RI (1986) Fluorescent carbocyanine dyes allow living neurons of identified origin to be studied in long term cultures. J Cell Biol 103:171-187.

Iijima N, Oohira A, Mori T, Kitabatake K, Kohsaka S (1991) Core protein of chondroitin sulfate proteoglycan promotes neurite outgrowth from cultured neocortical neurons. J Neurochem 56:706-708.

Jessell TM, Dodd J (1990) Floor plate-derived signals and the control of neural cell pattern in vertebrates. Harvey Lect 86:87-128.

Johnson GD, Nogueira-Araujo GM (1981) A simple method of reducing the fading of immunofluorescence during microscopy. J Immunol Methods 43:349-350.

Keynes RJ, Jaques KF, Cook GMW (1991) Axon repulsion during peripheral nerve segmentation. Development [Suppl] 2:131-139.

Koester SE, O'Leary DDM (1993) Connectional distinction between callosal and subcortically projecting cortical neurons is determined prior to axon extension. Dev Biol, in press.

Kuwada JY (1992) Growth cone guidance in the zebrafish central nervous system. Curr Opin Neurobiol 2:31-35.

Lafont F, Rouget M, Triller A, Prochiantz A, Rousselet A (1992) In vitro control of neuronal polarity by glycosaminoglycans. Development 114:17-29.

Lander AD (1990) Mechanisms by which molecules guide axons. Curr Opin Cell Biol 2:907-913.

Ietourneau PC, Condic MI, Snow DM (1992) Extracellular matrix and neurite outgrowth. Curr Opin Genet Dev 2:625-634.

Luskin MB, Shatz CJ (1985) Studies of the earliest generated cells of the cat's visual cortex: congeneration of the cells of the marginal zone and subplate. J Neurosci 5:1062-1075.

Marin-Padilla M (1971) Early prenatal ontogenesis of the cerebral cortex (neocortex) of the cal (Felis domestica). A Golgi study. I. The primordial neocortical organization. Z Anat Entwicklungsgesch 134: $117-145$.

Marin-Padilla M (1978) Dual origin of the mammalian neocortex and evolution of the cortical plate. Anat Embryol 152:109-126.

Mason CA, Godement P (1991) Growth cone form reflects interactions in visual pathways and cerebellar targets. In: The nerve growth cone (Letourneau PC, Kater SB, Macagno ER, eds), pp 405-424. New York: Raven.

McConnell SK, Ghosh A, Shatz CJ (1989) Subplate neurons pioneer the first axon pathway from the cerebral cortex. Science 245:978982.

McKeon RJ, Schreiber RC, Rudge JS, Silver J (1991) Reduction of neurite outgrowth in a model of glial scarring following CNS injury is correlated with the expression of inhibitory molecules on reactive astrocytes. J Neurosci 11:3398-3411.

Miller B, Sheppard AM, Pearlman AL (1992) Expression of two chondroitin sulfate proteoglycan core proteins in the subplate pathway of early cortical afferents. Soc Neurosci Abstr 18:778.

Miller BM, Chou L, Finlay BL (1993) The early development of thalamocortical and corticofugal projections. J Comp Neurol, in press.

Nakanishi S (1983) Extracellular matrix during laminar pattern formation of neocortex in normal and reeler mutant mice. Dev Biol 95: 305-316.

Nakanishi S, Derer P (1982) Localisation de la matrice extracellulaire au cours de la corticogenese de la souris normale et du mutant reeler. Biol Cell 42:8a.

Oakley RA, Tosney KW (1991) Peanut agglutinin and chondroitin6-sulfate are molecular markers for tissues that act as barriers to axon advance in the avian embryo. Dev Biol 147:187-206.

Oohira A, Matsui F, Matsuda M, Takida Y, Kuboki Y (1988) Occurrence of three distinct molecular species of chondroitin sulfate proteoglycan in the developing rat brain. J Biol Chem 263:1024010246.

Oohira A, Matsui F, Katoh-Semba R (1991) Inhibitory effects of brain 
chondroitin sulfate proteoglycans on neurite outgrowth from PC12D cells. J Neurosci 1 1:822-827.

Patterson PH (1988) On the importance of being inhibited, or saying no to growth cones. Neuron 1:263-267.

Pearlman AL, Broekelmann TJ, McDonald JA, Sheppard AM (1992) Stage-specific production of fibronectin in neocortical development: evidence for synthesis by both neurons and glia. Soc Neurosci Abstr 18:777.

Pindzola RR, Doller C, Silver J (1993) Putative inhibitory extracellular matrix molecules at the dorsal root entry zone of the spinal cord during development and after root and sciatic nerve lesions. Dev Biol 156:34-48.

Raedler E, Raedler A (1978) Autoradiographic study of early neurogenesis in rat neocortex. Anat Embryol (Berl) 154:267-284.

Rauch U, Gao P, Janetzko A, Flaccus A, Hilgenberg L, Tekotte $H$, Margolis RK, Margolis RU (1991) Isolation and characterization of developmentally regulated chondroitin sulfate and chondroitin/ keratin sulfate proteoglycans of brain identified with monoclonal antibodics. J Biol Chem 266:14785-14801.

Rauch U, Karthikeyan L, Maurel P, Margolis RU, Margolis RK (1992) Cloning and primary structure of neurocan, a developmentally regulated, aggregating chondroitin sulfate proteoglycan of brain. J Biol Chem 267:19536-19547.

Reichardt LF, Tomaselli KJ (1991) Extracellular matrix molecules and their receptors: functions in neural development. Annu Rev Neurosci 14:531-570.

Rickmann M, Chronwall BM, Wolff JR (1977) On the development of non-pyramidal neurons and axons outside the cortical plate: the early marginal zone as a pallial anlage. Anat Embryol (Berl) 151:285307.

Ruoslahti E (1989) Proteoglycans in cell regulation. J Biol Chem 264: 13369-13372.

Sancs JR (1992) Basement membrane molecules in the vertebrate nervous system. In: Molecular and cellular aspects of basement membranes (Timple R, ed), pp 67-87. New York: Academic.

Schwab ME, Kapfhammer JP, Bandtlow CE (1993) Inhibitors of neurite growth. Annu Rev Neurosci 16:565-595.

Schwartz ML, Rakic P, Goldman-Rakic PS (1991) Early phenotype expression of cortical neurons: evidence that a subpopulation of migrating neurons have callosal axons. Proc Natl Acad Sci USA 88: $1354-1358$

Sheppard AM, Hamilton SK, Pearlman AL (1991) Changes in the distribution of extracellular matrix components accompany early morphogenetic events of mammalian cortical development. J Neurosci 11:3928-3942.

Shoukimas GM, Hinds JW (1978) The development of the cerebral cortex in the embryonic mouse: an electron microscopic serial section analysis. J Comp Neurol 179:795-830.

Smart IHM, Smart M (1982) Growth patterns in the lateral wall of the mouse telencephalon. I. Autoradiographic studies of the histogenesis of the isocortex and adjacent areas. J Anat 134:273-298.

Snow DM, Letourneau PC (1992) Neurite outgrowth on a step gradient of chondroitin sulfate proteoglycan (CS-PG). J Neurobiol 23:322336.

Snow DM, Lemmon V, Carrino DA, Caplan AI, Silver J (1990) Sulfated proteoglycans in astroglial barriers inhibit neurite outgrowth in vitro. Exp Neurol 109:111-130.

Snow DM, Steindler DA, Silver J (1990) Molecular and cellular characterization of the glial roof plate of the spinal cord and optic tectum: a possible role for a proteoglycan in the development of an axon barrier. Dev Biol 138:359-376.

Snow DM, Watanabe M, Letourneau PC, Silver J (1991) A chondroitin sulfate proteoglycan may influence the direction of retinal ganglion cell outgrowth. Development 113:1473-1485.

Steindler DA (1993) Glial boundaries in the developing nervous system. Annu Rev Neurosci 16:445-470.

Steindler DA, Faissner A, Schachner M (1990) Brain "cordones": transient boundaries of glia and adhesion molecules that define developing functional units. Commun Dev Neurobiol 1:29-60.

Stewart GR, Pearlman AL (1987) Fibronectin-like immunoreactivity in the developing cerebral cortex. J Neurosci 7:3325-3333.

Tosney KW (1988) Proximal tissues and patterned neurite outgrowth at the lumbosacral level of the chick embryo: partial and complete deletion of the somite. Dev Biol 127:266-268.

Tosney KW, Landmesser LT (1984) Pattern and specificity of axonal outgrowth following varying degrees of chick limb bud ablation. $\mathrm{J}$ Neurosci 4:2518-2527.

Tosney KW, Landmesser L (1985) Development of the major pathways for neurite outgrowth in the chick hindlimb. Dev Biol 109:193214.

Tosney KW, Oakley RA (1990) The perinotochordal mesenchyme acts as a barrier to axon advance in the chick embryo: implications for a general mechanism of axonal guidance. Exp Neurol 109:75-89.

Verna JM, Fichard A, Saxod R (1989) Influence of glycosaminoglycans on ncurite morphology and outgrowth patterns in vitro. Int J Dev Neurosci 7:389-399.

Wood JG, Martin S, Price DJ (1992) Evidence that the earliest generated cells of the murine cerebral cortex form a transient population in the subplate and marginal zone. Dev Brain Res 66:137-140.

Woodward WR, Coull BM (1984) Localization and organization of geniculocortical and corticofugal fiber tracts within the subcortical white matter. Neuroscience 12:1089-1099.

Woodward WR, Chiaia N, Teyler TJ, Leong L, Coull BM (1990) Organization of cortical afferent and efferent pathways in the white matter of the rat visual system. Neuroscience 36:393-401.

Yaginuma H, Oppenheim RW (1991) An experimental analysis of in vivo guidance cues used by axons of spinal interneurons in the chick embryo: evidence for chemotropism and related guidance mechanisms. J Ncurosci 11:2598-2613.

Zaremba S, Naegele JR, Barnstable CJ, Hockfield S (1990) Neuronal subsets express multiple high-molecular-weight cell-surface glycoconjugates defined by monoclonal antibodies Cat-30 I and VCI.1. J Neurosci 10:2985-2995. 